\title{
Using Triadic Semiotics in Storytelling
}

\author{
Chien-Wen Lin', Ta-Long Lin² \\ ${ }^{1}$ Department of Applied Arts, Fu Jen Catholic University, New Taipei City, Taiwan \\ ${ }^{2}$ Department of Fine Arts, National Taiwan Normal University, Taipei City, Taiwan \\ Email: pam@mail.fju.edu.tw, findart@ntnu.edu.tw
}

Received 16 September 2014; revised 23 October 2014; accepted 6 November 2014

Copyright (C) 2014 by authors and Scientific Research Publishing Inc.

This work is licensed under the Creative Commons Attribution International License (CC BY).

http://creativecommons.org/licenses/by/4.0/

(c) (i) Open Access

\begin{abstract}
Researchers of this study have been making animation-related production and teaching for more than twenty years. Telling Stories with Pictures is a very common method for language and design teaching. And "idea pitching" is just like Telling Stories with Pictures; it is a significant process in developing a story for professional animation companies. This study focused on using Peirce's Triadic Semiotics (icon-index-symbol semiotic triangle) with Story Cubes (Story Dices) in storytelling. By laboratory observation method, a team of students carried out the experiment contrast. After the introduction of Triadic Semiotics, testees would make stories having some associations and implications; therefore, there would be more possibilities and more imaginations in the story arrangement and structure. It is expected that the study results may provide effective recommendations for the production education of animation. In other design fields or knowledge management, more dynamic thinking methodology may be figured out accordingly as well.
\end{abstract}

\section{Keywords}

\section{Storytelling, Triadic Semiotic, Story Dice}

\section{Introduction}

"Story" is the development essence in an animation. Pixar, a famous Disney animation company in Hollywood, has a motto circulating inside it-“story is king” (Canemaker, 2010). How to tell a story is always a good issue. Through the packaging of storytelling, the transmission and communication of information can touch the core effectively. "Storytelling" is not only used to express plots in broadcasting/movie/TV programme, product marketing, education and communication. In recent years, the process of product design has relied on story development that can lead design concept in the whole designing process. Stories make users focus on their experience rather than unfamiliar skills. Stories help users receive feedback, which is more accurate, detailed and honest. In the aspect of product research \& development, it is found that using a story as foundation can be valuable in the whole cycle of designing. From the visionary inspiration in the early stage, concept definition, spe- 
cification requirements and design to prototype creation, development and product introduction, stories help designers and developers submerge in the future users' operating status. Stories help designers identify what functions shall be useful (Gruen, Rauch, Redpath, \& Ruettinger, 2002).

In animation producing and teaching, the researchers of this study often encounter a kind of situation wherein direct statement of story or roles dialog need to be presented so as to facilitate subtitling. This, however, lacks of some brewing and waiting for implication; therefore, stories would easily become straightforward or less interesting without association stimulation.

Story Dices and Story Cubes are a kind of cubes with six different pictures on six different sides, which has been widely adopted in the field of entertainment, education, language institutes, storytelling and creativity for many years. Rory's Story Cubes (as Figure 1) are a popular tool for creativity teaching at school and home, but not everyone could tell a creative story after using it. The original storytelling was just like mirror reflection. Most students saw a picture and directly told the story associated to the picture contents/appearance.

This study focused on using Peirce's Triadic Semiotics (icon-index-symbol semiotic triangle) with Story Dices (Story Cubes) in storytelling. There were two experimental steps. Experiment 1: each testee used story dice to select four pictures randomly and testees told a little story based on the four pictures. Experiment 2: to the same testees, the Triadic Semiotics was provided and testees told the story again based on the four pictures.

After the introduction of Triadic Semiotics, testees would make stories having some associations and implications; therefore, there would be more possibilities of having more imagination in the story arrangement and structure. With the inspiration from Peirce's semiotics and the application assistance of Story Cubes, students' storytelling capabilities in producing animation have been improved. Tested students' storytelling performance and changes to story contents and creativity were recorded. Therefore, effective recommendations for students to build capability of storytelling in producing animation can be proposed. This kind of concept of using Peirce's Triadic Semiotics (icon-index-symbol semiotic triangle) with Story Cubes (Story Dices) in storytelling could also be applied to those fields like creativity design thinking, communication and of course idea pitching for animation production process.

\section{Story Dices}

"Idea pitching" is just like Telling Stories with Pictures. It is a significant process in developing a story for professional animation companies. The concept of Telling Stories with Pictures can be traced back to ancient era. Scholars of comic books believe that it is a great milestone when Switzerland artist painted sarcastic cartoon with subtitles under the frame in the $19^{\text {th }}$ century (McGrath, 2004). However, Story Dice takes Telling Stories with Pictures to a higher level. Zhou, Cheok, Pan and Li (2004) mention that storytelling is an important part of human culture both in education and entertainment and they develop "Magic Story Cube" to explore the application of cube interface to the area of interactive storytelling for children. Story Dice has been widely used in composition, storytelling, language teaching and innovation. Before there is solid Story Dice and in recent years there are various Story Dice App for mobile phones, such as "Story Dice” and "Rory's Story Cubes” (The Creativity Hub Ltd., 2007). In Druin and Fast's study (2002), 8-year-old children used their self-made story dice, by

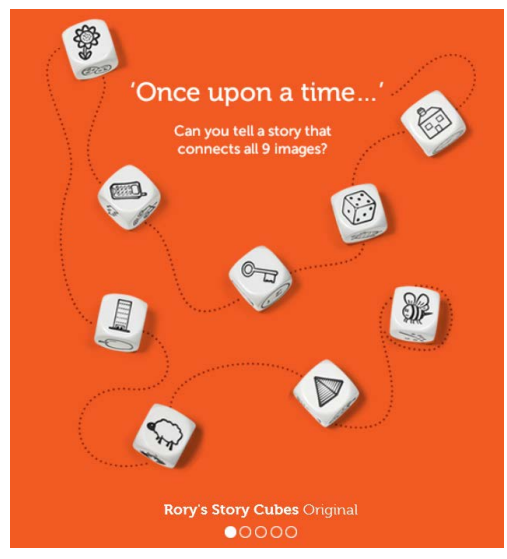

Figure 1. Rory’s story cubes. 
which children also have different order to tell stories. Story Dice is not only helpful to children's storytelling, but also beneficial to children's thinking development and structure. This study adopted Story Dice App to conduct experiment and observation.

People use Story Dices (Story Cubes) to get random pictures to tell stories. Random pictures somehow help story tellers to start their stories and end the stories. But usually most people get the story result simply by what they see (pictures) rather than what they can get (story). Most people would get stuck at physical stage, and forgot to use their creativity, imagination about how to "link" all the pictures while telling story, it's not just a picture follow a picture.

\section{Triadic Semiotic}

Charles Sanders Peirce, an American pragmatic philosopher, and Ferdinand de Saussure, a Swiss linguist, are regarded as two major contributors of modern semiotics, or semiology. Both are considered two founding fathers of mathematical symbol logic. Saussure called it semiology and Peirce called it semiotics.

The existence of signs does not come from signs per se. It is being adopted and assigned according to those people who give definition or explanation. There is not any signs can solely exist. On the other word, no any sign can exist with other signs incoherently. Following Aristotle's (384BC-322BC) ten categories of existence and Immanuel Kant's (1724-1804) twelve categories of mind, Charles Sanders Peirce (1839-1914) was the first scholar defining signs and proposing sign relation (Walther, 2002). This study is mainly developed from Peirce's Triadic Semiotics (icon-index-symbol semiotic triangle). Table 1 is a summary made by researchers of this study showing sign property by linguist, Karl Bühler, "sign and design" by Max Bense and sign category by Charles Sanders Peirce.

Signs deliver immediate and relevant simple information; symbols, however, are the implied meanings behind visional pictures or signs (Bruce-Mitford \& Wilkinson, 2009). Commonly sign relation has been divided into three elements-icon, index and symbol, which were firstly adopted by Ch. W. Morris, who also introduced semantics into semiotics. These three elements have been widely used in fields, such as science, linguistics, logic, mass communication, aesthetics, movie/theatre and animation art, etc.

Signs can be regarded as triadic relation of a group of three: $\mathrm{ZR}=\mathrm{R}(\mathrm{M}, \mathrm{O}, \mathrm{I})$. Any sign $\mathrm{Z}$ can be regarded as a media $\mathrm{M}$, which can represent an object $\mathrm{O}$, and imply something to an interpreter I. Each operating of application signs can be called symbolic process "Semiose". Through the introduction of triadic relation, signs demonstrate models of fundamental innovation (or message), creativity elements or options (Walther, 2002).

Charles Sanders Peirce (1839-1914) defined the three elements of signs. "Icon" represents signs with the semblance of target object. They could be produced by realistically copy or mimicking. By watching signs themselves, the meaning of signs could be understood purely, e.g. the silhouette of high-heels and house. "Index" represents the direct connection to the target object. Index signs will provide association to the target object, e.g. the arrow of showing direction, the signs of human body showing men's toilet and women's toilet. "Symbol", however, has no relation to the target object; without semblance and connection, symbol plays by free statement or customary rules. Symbol needs to be learned to understand its meaning, e.g. numbers or punctuation or even some unrelated connotation (Table 2).

Following Table 1, as below Figure 2 was created according to sign property by linguist, Karl Bühler, "sign and design” by Max Bense and Triadic Semiotics (Icon-Index-Symbol semiotic triangle) by Charles Sanders Peirce.

\section{Experiment}

This experiment was conducted in three different classes (totaling 31 people). First of all, each testee used Story Dice App in iphone, through projector, to throw the dice and four icons appeared accordingly. Testees then took a photo of these four icons as a record and testees were asked to structure a one-minute story, in five minutes, according to the four icons (as Figure 3). Stories should be written and then shared with other testees. After everyone's story has been told, examiner explained the individual meaning of icons by Peirce's Triadic Semiotics (icon-index-symbol semiotic triangle). After this explanation, testees had brand new imagination about icon meanings. They did not merely perceive what they saw. Then testees were requested to ponder those icons they have received and made their own table (as Table 3) by icon, index and symbol properties. Each testees then created a new one-minute story. 
Table 1. Summary made by researchers of this study.

\begin{tabular}{|c|c|c|c|c|c|}
\hline Sign property & Dimension & Sign and design & $\begin{array}{c}\text { Symbolic } \\
\text { function/element/possibility }\end{array}$ & $\begin{array}{l}\text { Character of } \\
\text { triadic sign }\end{array}$ & $\begin{array}{l}\text { Peirce's triadic relation } \\
\text { of sign category }\end{array}$ \\
\hline Representation & $\begin{array}{l}\text { Material } \\
\text { (texture) }\end{array}$ & $\begin{array}{l}\text { Noun-icon-feature } \\
\text { sign }\end{array}$ & Style & How & Representation relation \\
\hline Expression & Semantic (type) & $\begin{array}{l}\text { Entitle-index-single } \\
\text { sign }\end{array}$ & Information & What & Object relation \\
\hline Delivery & Composition (structure) & $\begin{array}{l}\text { Argument-symbol-regular } \\
\text { sign }\end{array}$ & Communication & Why & Interpretant relation \\
\hline
\end{tabular}

Table 2. Examples of Peirce’s triadic semiotics (icon-index-symbol semiotic triangle).

Sign elements
$\begin{gathered}\text { Icon } \\ \text { (physical) }\end{gathered}$
$\begin{gathered}\text { Index } \\ \text { (physiological) }\end{gathered}$
$\begin{gathered}\text { Symbol } \\ \text { (psychological) }\end{gathered}$

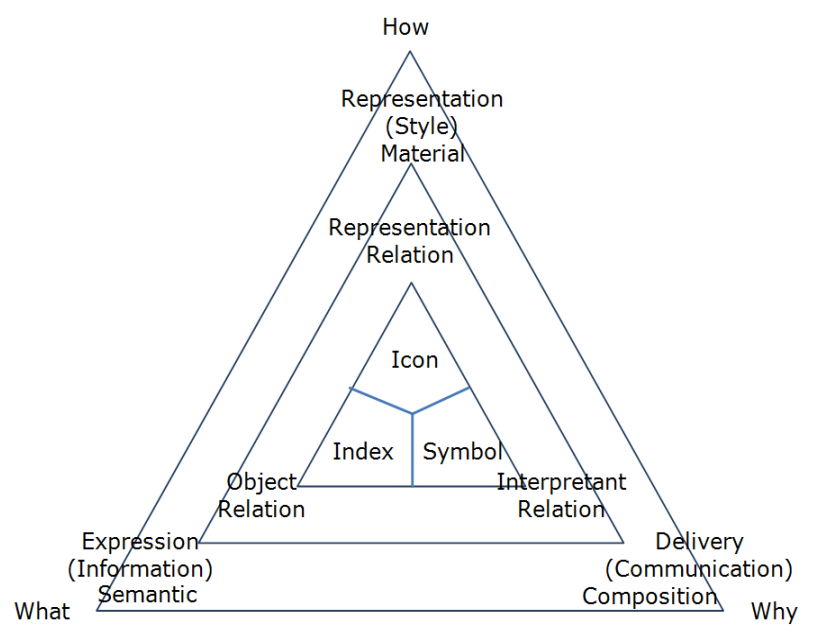

Figure 2. This triangle model was by researchers of this study.

\subsection{Real Example}

Set up the experiment environment as Figure 4.

\subsubsection{Before Introduction of Peirce's Triadic Semiotics (Icon-Index-Symbol Semiotic Triangle)}

According to the four icons (as Figure 5), student $\mathrm{S}$ wrote one-minute story as below:

In a dark and gusty night, a beam of green light projected from the "sky". An "alien" just arrived! It arrived in the village of "bear" and wanted to see the life of bears. But mindlessly the UFO was struck by lightning and a 
Table 3. Based on triadic aspects—icon, index and symbol, testees created more imagination for the four icons from using Story Dice App in iphone.

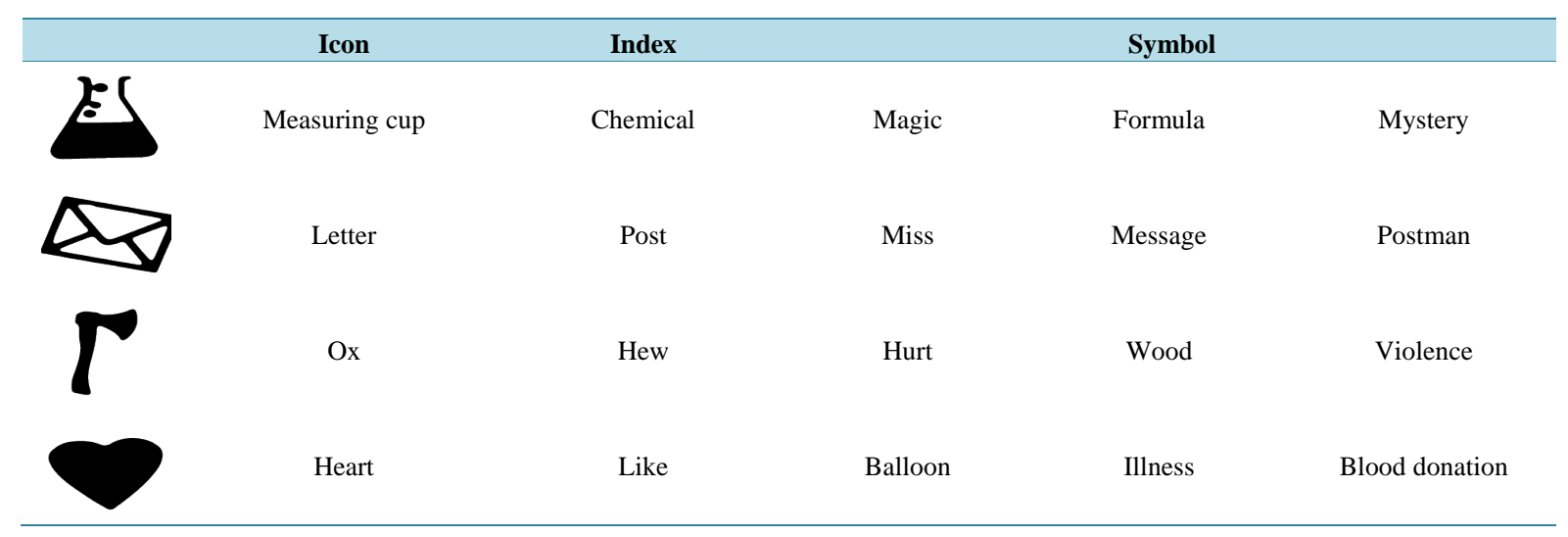

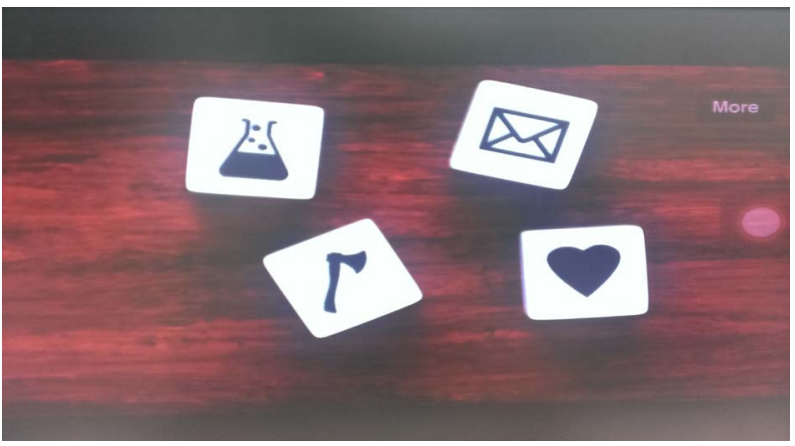

Figure 3. The four icons in dice, which was thrown by a testee with Story Dice App in iphone.

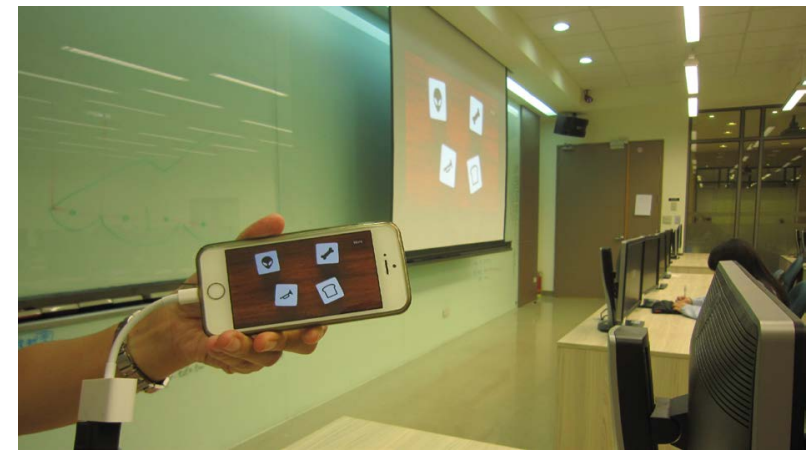

Figure 4. Use projector to deliver Story Dice App in iphone for testees.

piece of "part" bounced up before it made a forced-landing on the fruit farm outside the village. There was a bear inside the farm; it was stealing grapes. The ejected part from the UFO was hitting the bear's whole basket of grapes. All grapes were ruined. The bear was very angry. He stood up to have a row with the alien. The alien was depressed that it was seen by the bear; therefore, it knocked out the bear.

On the next day, the bear found that it lay down on the entrance of the village, with a bunch of bananas in hand.

\subsubsection{After Introduction of Peirce's Triadic Semiotics (Icon-Index-Symbol Semiotic Triangle)}

After being introduced with Peirce's Triadic Semiotics (Icon-Index-Symbol semiotic triangle), student S reconsidered the implications and meanings of these four icons (as Table 4) and created a new story as follows: 


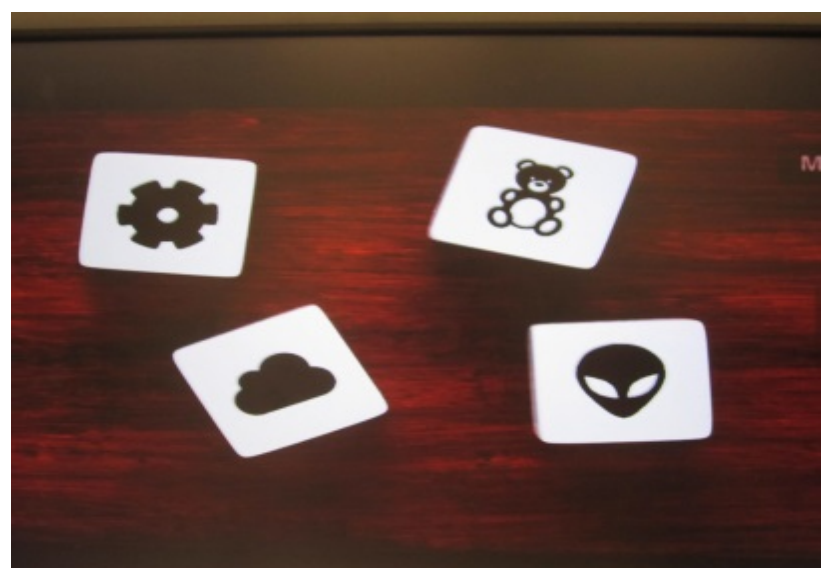

Figure 5. The four icons of student S.

Table 4. Student S used triadic model to created more implications and associations.

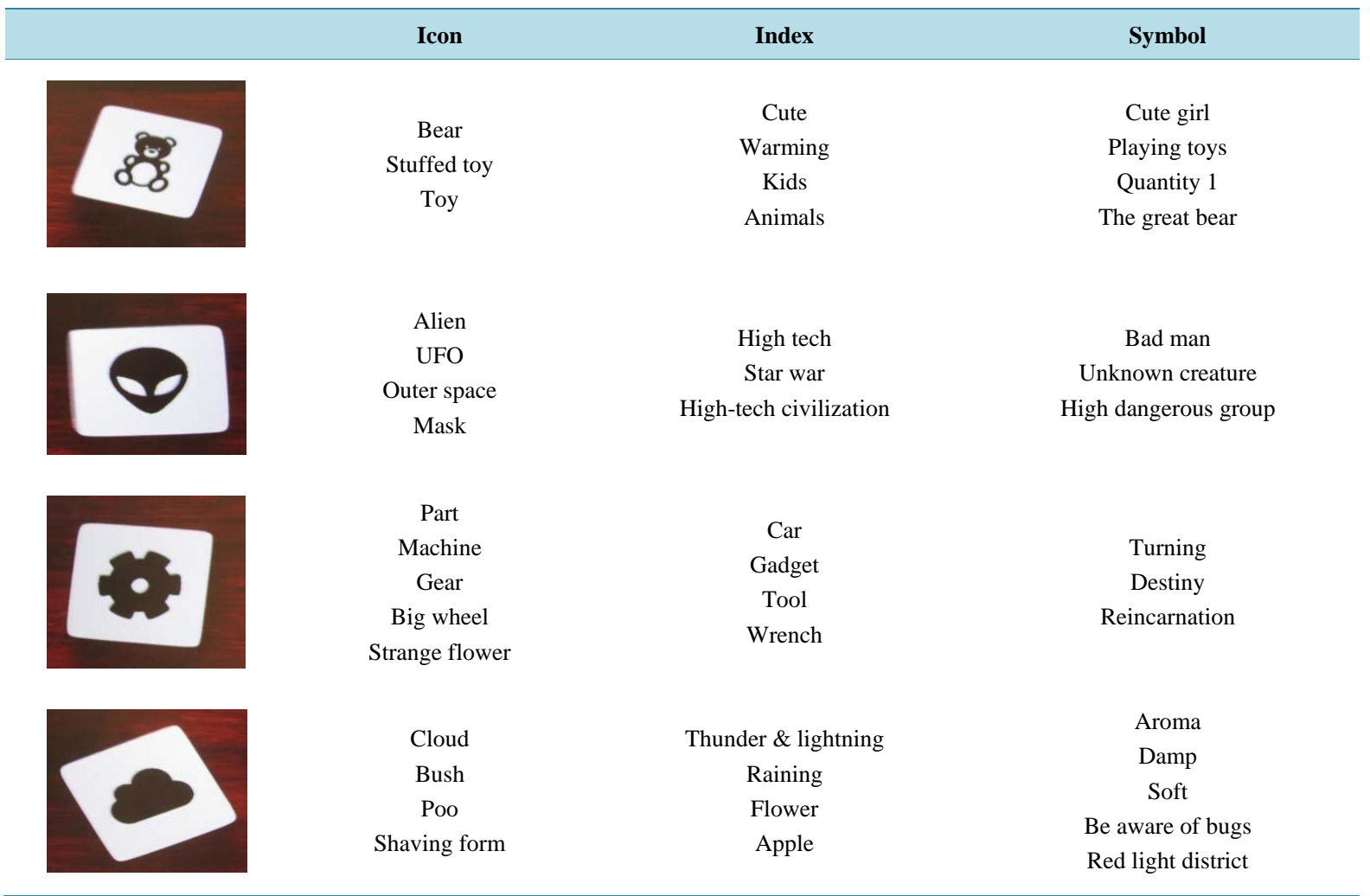

\subsubsection{Imagination Version}

In year of 5019, the earth is no longer inhabitable. After wandering in the outer space for years, human being has prepared to invade other planets. They got onto a "bear-like" UFO and attacked the planet RTK576. But the aliens on RTK576 should not be underestimated. They invented a "cloud" controller. By utilizing artificial clouds, RTK576 produced lots of thunder and lightning, which hit humans' bear-like UFO. A piece of “part” in the UFO was falling down and the UFO had to make a forced-landing on RTK576. No sooner did humans get off the UFO, than RTK aliens stopped attack. Humans were very surprised. RTK aliens took off their masks and it turned out that they were human being, too. It turned out that a thousand years ago humans' space ships separated by accident and they split into two worlds without connection. Now the fate brought them together and they will never be a part any more. 


\section{Discussion and Conclusion}

After the experiment, it is found that most testees would tell stories according to those icons they see. When we see an icon, the intuitive representation comes out most quickly and directly. With the guidance of semiotics, not only can testees create more possibilities and triggers in pondering their stories, but also produce more diversified associations in interpreting icons. Testees agreed that if they had received semiotic reminder earlier, it would have been beneficial in structuring their animation stories. It is also found that in the process of icon and index, testees have fewer obstacles. But in the process of symbol, bouncing or illogical thinking has been less attempted. For the related teaching in the future, this could be encouraged and tried; perhaps, there will be more unbelievable or unpredictable sparks and associations to be created.

\section{References}

Bruce-Mitford, M., \& Wilkinson, P. (2009). Signs \& Symbols: An Illustrated Guide to Their Origins and Meanings. Taipei.

Canemaker, J. (2010). Two Guys Named Joe: Master Animation Storytellers Joe Grant and Joe Ranft. USA: Disney Editions.

Druin, A., \& Fast, C. (2002). The Child as Learner, Critic, Inventor, and Technology Design Partner: An Analysis of Three Years of Swedish Student Journals. International Journal of Technology and Design Education, 12, 189-213. http://dx.doi.org/10.1023/A:1020255806645

Gruen, D., Rauch, T., Redpath, S., \& Ruettinger, S. (2002). The Use of Stories in User Experience Design. International Journal of Human-Computer Interaction, 14, 503-534. http://dx.doi.org/10.1080/10447318.2002.9669132

McGrath, C. (2004). Not Funnies. New York Times Magazine.

Walther, E. (2002). Zeichen: Aufsätzezur Semiotik. VDG, Verlag und Datenbank für Geisteswissenschaften.

Zhou, Z., Cheok, A. D., Pan, J., \& Li, Y. (2004) Magic Story Cube: An Interactive Tangible Interface for Storytelling. Proceedings of the 2004 ACM SIGCHI International Conference on Advances in Computer Entertainment Technology. 
Scientific Research Publishing (SCIRP) is one of the largest Open Access journal publishers. It is currently publishing more than 200 open access, online, peer-reviewed journals covering a wide range of academic disciplines. SCIRP serves the worldwide academic communities and contributes to the progress and application of science with its publication.

Other selected journals from SCIRP are listed as below. Submit your manuscript to us via either submit@scirp.org or Online Submission Portal.
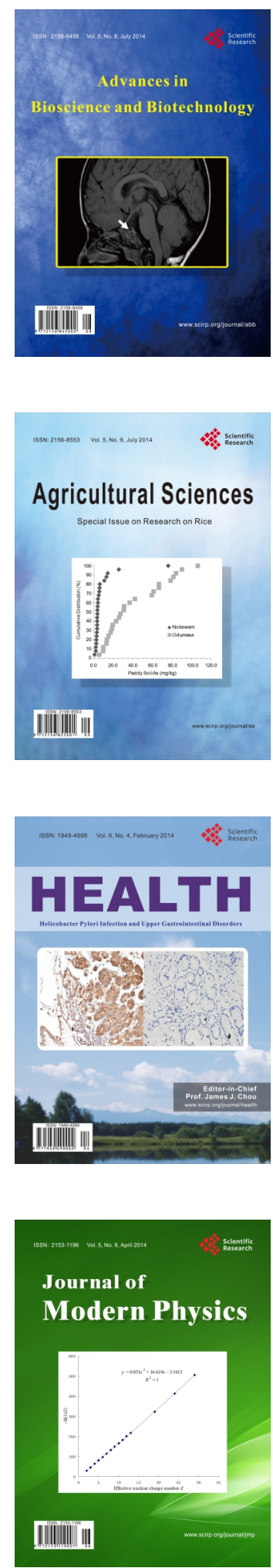
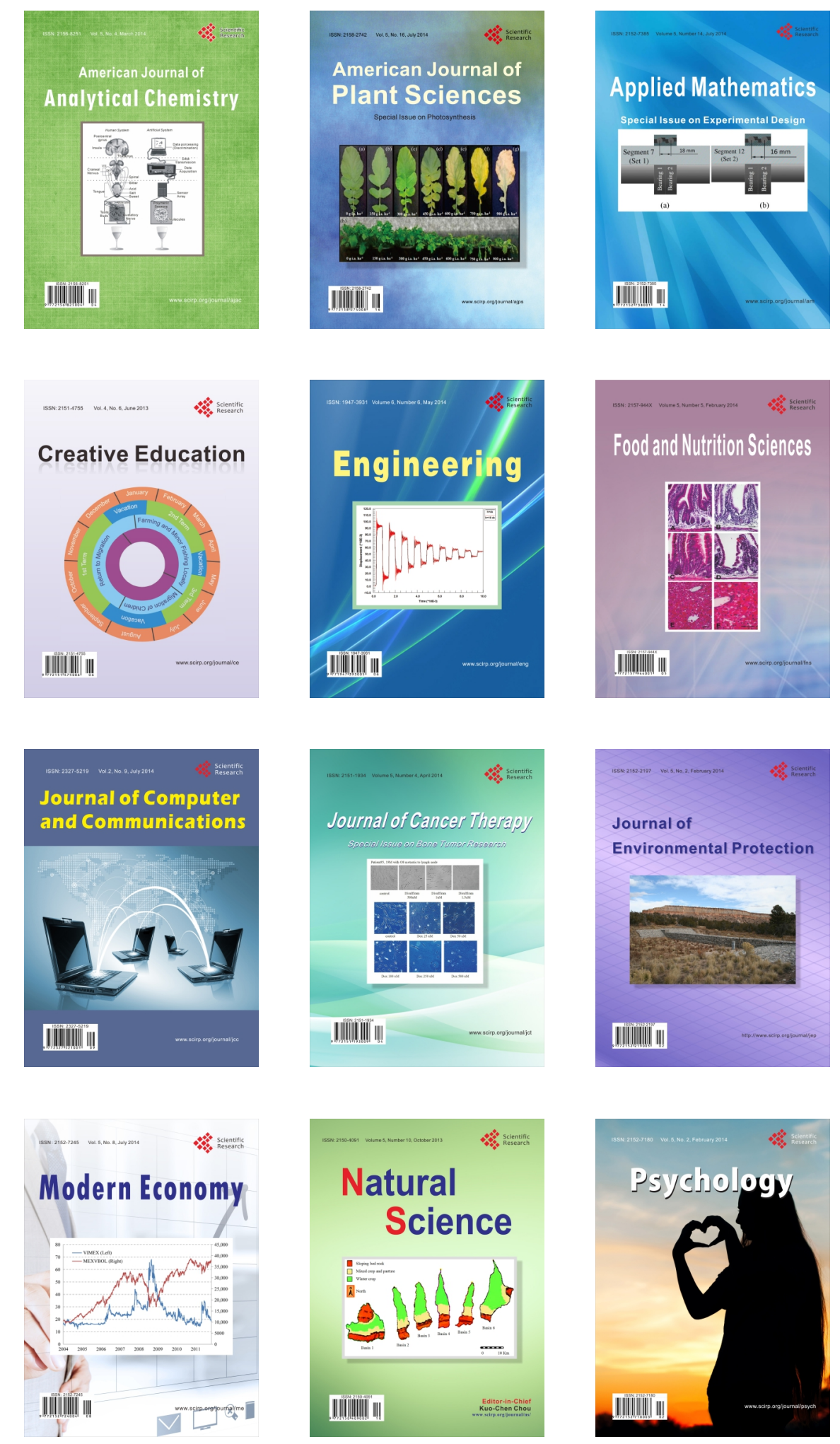